\title{
SCHISTOSOMA HAEMATOBIUM: PREVALENCE AND SOCIO-ECONOMIC FACTORS AMONG STUDENTS IN CAPE COAST GHANA.
}

\author{
OKANLA E.O *, AGBA B.N. AND AWOTUNDE J.O \\ Department of Biological Sciences, University of Ilorin, Ilorin Nigeria
}

\begin{abstract}
Prevalence of Schistosoma haematobium infections was assessed among 160 students of Twohofo Holy International School, Cape Coast, Ghana. Overall prevalence was $34.4 \%$, with males and females having prevalence of $32.3 \%$ and $35.8 \%$ respectively. Age group 6-8 years had $30 \%$ while $24.2 \%$ were infected in age group 9-11 years. Prevalence was $48 \%$ in age group $12-14$ years and $50 \%$ in age group 15-17 years. Parental occupation had effect on prevalence with children of self employed parents showing significantly higher prevalence than children of salaried employees of government and private companies. Knowledge of the disease was very low among the subjects.
\end{abstract}

Keywords: Schistosoma haematobium, prevalence, Cape coast, Ghana, students

\section{INTRODUCTION}

Schistosomiasis is a disease caused by blood flukes of the family Shistosomatidae. They infect different vertebrates, but three of them in particular cause disease in man. These are Schistosoma mansoni, S. Japonicum and $S$. haemaiobium (Adams and Maegraith, 1976). The first two are found in the veins of the large intestine and small intestine respectively while haematobium is found in the veins of the bladder. Among other places, $S$. haematobium is found widespread in Africa. Many factors influence the epidemiology of schistosomiasis. Edungbola (1980) reported the relationship between water utilization and schistosomiasis, while Okanla (1991), reported that parental occupation may be a factor in contracting schistosomiasis.

Surveillance for schistosomiasis is very important in establishing endemicity and in the planning of control operations. Many areas of the world are yet unsampled while some have been sampled without making definite data available on the socio-economic factors that have influence on prevalence in such localities. This study was designed to look at a number of parameters including socio-economic contributors to the prevalence of $S$. haematobium infections among the students of
Twohofo Holy International School in Cape Coast, Ghana.

\section{MATERIALS AND METHODS Study area:}

Akotokyir is in the Cape Coast district of the Central Region, Ghana. It is located between latitude $5^{\circ} 30^{\prime} \mathrm{N}$ and longitude $101^{\prime}$ and $1013^{\prime} \mathrm{W}$ of the Greenwich Meridian. It lies $2.2 \mathrm{~km}$ from University of Cape Coast. The vegetation is mainly Savannah. The Kakum river flows through the area. This attracts ctivities such as bathing, swimming, laundry and other activities. Information obtained from the Regional Health office indicated that urinary schistosomiasis is prevalent in the area, but useful data were not available.

\section{Pre-sampling formalities}

A total of 160 pupils comprising 68 males and 92 females were involved in the study. They included students in Basic Ito Basic 6 (i.e. Primary Ito Primary 6 ) of the Basic Educational System as it is known in Ghana. Weeks before sampling started, a letter was sent to the Head teacher of the School to give him an idea of what the study was about and to seek his cooperation. Students were given letters of consent to be signed by their parents as only those who obtained 
parental consent were included in the study. On the day before the sampling further notification was made to the Head teacher.

On the day of sampling, the Head teacher had got the students ready and a brief explanation was made to the students to let them know what schistosomiasis is and to instruct them on how to obtain the samples correctly.

\section{Collection of samples.}

All samples were collected between 12.00 noon and 2.00 p.m. (Mahmoud, 1987). Urine samples were collected in graduated plastic bottles, Subjects were told to empty their bladder completely into the bottle and put on the lid tight. As the students arrived one by one each was given a serial number. This was immediately pasted on the corresponding sample also.

\section{Collection of other data.}

The weight in kilograms and height in centimetres was obtained for each subject. Information on age, parental occupation and residence history (i.e. whether subject lived in Akotokyir or elsewhere) were also obtained. Further information was obtained on whether subjects had any knowledge of the disease, and

on the subject's history of water contact.

\section{Examination of urine samples for eggs of S. haematobium}

The method of Okanla (1991) was used. All samples were taken to the laboratory immediately and the total volume of urine passed by each subject was recorded Samples were allowed to settle for 30 mins. The urine in each sample was drawn off with an aspirator leaving the last $10 \mathrm{ml}$. In the bottle. The content of each bottle was shaken to suspend the sediment and was emptied into a $20 \mathrm{ml}$. centriftige tube. The serial number for each sample was carefully transferred so as not to get the samples mixed up. The tubes were centrifuged at $1000 \mathrm{rpm}$ for 5 $\mathrm{mm}$. The top $9 \mathrm{ml}$. was aspirated off. The sediment was re-suspended in the remaining $1 \mathrm{ml}$. A Pasteur pipette, which was calibrated to discharge $1 \mathrm{ml}$. in 20 drops, was used to release I drop of the sample unto a microscope slide. A cover slip was placed on it and all haematobium eggs present were counted under the 10x objective of a light microscope. The number of eggs counted in 1 drop was multiplied by 20 to obtain the number in $1 \mathrm{ml}$., which is also the total eggs passed in the total volume of urine originally obtained. The number in $10 \mathrm{ml}$. of urine was then calculated. This is important for determination of epidemiological implications.

\section{RESULTS}

A total of 160 subjects (68 males and 92 females) were examined $S$. haematobium was found in males and females alike A total of 22 males and 33 females were positive. This gave prevalence of $32.3 \%$ for the males and $35.8 \%$ for the females. Overall prevalence was $34.4 \%$ (Table 1).

Prevalence by age showed increase in $S$. haematobium infection with age except in age group 9-11 years which showed a decrease (Table 2).

Table 1.

Prevalence of urinary schistosomiasis among pupils of Twohofo Holy International School.

\begin{tabular}{lllllll}
\hline \multirow{2}{*}{ CLASS } & \multicolumn{5}{c}{ MALES } & \multicolumn{5}{c}{ FEMALES } & TOTAL \\
\cline { 2 - 7 } & $\begin{array}{l}\text { Number } \\
\text { Examined }\end{array}$ & $\begin{array}{l}\text { Number (\%) } \\
\text { Infected }\end{array}$ & $\begin{array}{l}\text { Number } \\
\text { Examined }\end{array}$ & $\begin{array}{l}\text { Number }(\%) \\
\text { Infected }\end{array}$ & $\begin{array}{l}\text { Total No } \\
\text { Examined }\end{array}$ & $\begin{array}{l}\text { Total No (\%) } \\
\text { Infected }\end{array}$ \\
\hline BASIC 1 & 12 & $7(58.3)^{*}$ & 19 & $5(26.3)^{*}$ & 31 & $12(38.7)^{\star *}$ \\
\hline BASIC 2 & 11 & $3(27.2)^{*}$ & 17 & $10(58.8)^{*}$ & 28 & $13(46.4)^{* *}$ \\
\hline BASIC 3 & 12 & $1(8.3)^{*}$ & 10 & $2(20.0)^{*}$ & 22 & $3(13.6)^{\star *}$ \\
\hline BASIC 4 & 16 & $4(25.0)^{*}$ & 16 & $3(18.7)^{*}$ & 32 & $7(21.8)^{* *}$ \\
\hline BASIC 5 & 12 & $3(25.0)^{*}$ & 17 & $7(41.2)^{*}$ & 29 & $10(34.4)^{* *}$ \\
\hline BASIC 6 & 5 & $4(80.0)^{*}$ & 13 & $6(46.1)^{*}$ & 18 & $10(55.5)^{* *}$ \\
\hline TOTAL & 68 & 22 & 92 & $33(35.8)^{*}$ & 160 & $55(34,4)^{* *}$ \\
\hline
\end{tabular}

* Percentage of students that were infected; ${ }^{* *}$ Total percentage of infected students. 
Table 2.

Prevalence of $S$. haematobium infection by age.

\begin{tabular}{llll}
\hline $\begin{array}{l}\text { Age } \\
\text { (Yrs) }\end{array}$ & $\begin{array}{l}\text { Total } \\
\text { Examined }\end{array}$ & $\begin{array}{l}\text { Number } \\
\text { Infected }\end{array}$ & $\begin{array}{l}\% \\
\text { Infected }\end{array}$ \\
\hline $6-8$ & 40 & 12 & 30.0 \\
\hline $9-11$ & 62 & 15 & 24.2 \\
\hline $12-14$ & 56 & 27 & 48.2 \\
\hline $15-17$ & 2 & 1 & 50.0 \\
\hline TOTAL & $\mathbf{1 6 0}$ & $\mathbf{5 5}$ & $\mathbf{3 4 . 4}$ \\
\hline
\end{tabular}

Table 3: Prevalence of $S$. haematobium infection by paternal occupation

\begin{tabular}{llll}
\hline \multicolumn{1}{l}{ by paternal occupation } & \\
& $\begin{array}{l}\text { *Blue/White } \\
\text { Collar }\end{array}$ & Other Jobs & Total \\
& & & \\
\hline NO & 89 & 71 & 160 \\
EXAMINED & & & 80 \\
\hline MALES & 45 & 35 & 22 \\
\cline { 2 - 4 } INFECTED & $5(11.1 \%)$ & $17(48.6 \%)$ & 80 \\
\hline FEMALES & 44 & 36 & 33 \\
\cline { 2 - 4 } INFECTED & $15(34.0 \%)$ & $18(50.0 \%)$ & $35(34.4 \%$ \\
\hline TOTAL & $20(22.4 \%)$ & $35(49.3 \%)$ & 5 \\
INFECTED & & &
\end{tabular}

*Upper class/Lower class salaried employees of Government and the private sector.

Table 4: Prevalence of $S$. haematobium infection by maternal occupation

\begin{tabular}{llll}
\hline \multicolumn{3}{l}{ by maternal occupation } \\
& $\begin{array}{l}\text { *Blue/White } \\
\text { Collar }\end{array}$ & Other Jobs & Total \\
\hline $\begin{array}{l}\text { NO } \\
\text { EXAMINED }\end{array}$ & 82 & 78 & 160 \\
\hline MALES & 32 & 36 & 68 \\
\cline { 2 - 4 } INFECTED & $7(21.8 \%)$ & $15(41.7 \%)$ & 22 \\
\hline FEMALES & 50 & 42 & 92 \\
\cline { 2 - 4 } INFECTED & $15(34.0 \%)$ & $18(50.0 \%)$ & 33 \\
\hline TOTAL & $20(24.3 \%)$ & $35(44.8 \%)$ & $55(34.4 \%$ \\
INFECTED & & & \\
\hline
\end{tabular}

*Upper class/Lower class salaried employees of Government and the private sector.

Age group 6-8 years had a prevalence of $30.0 \%$, while age group $9-11$ years had $24.2 \%$. Age group $12-14$ years had $48.2 \%$. Only 2 subjects were sampled in age group 15-17 tears. One of them was infected giving a prevalence of $50.0 \%$.

Prevalence by paternal occupation is presented in table 3 . Among those whose fathers have white collar/blue collar jobs, $11.1 \%$ of the males and $34.0 \%$ of the females were infected while in the other jobs group $48.6 \%$ of the males and $50.0 \%$ of the females were infected. Also, prevalence by maternal occupation has $21.8 \%$ of the males and $26.0 \%$ of the females infected in the white collar/blue collar group while $41.7 \%$ of the males and $47.6 \%$ of the females were infected in the other jobs group (Table 4)

Table 5 shows prevalence by residency. Among the 146 subjects who lived in the study area, 51 (were infected while only 4 out of 14 subjects who lived outside of the study area Akotokyir were infected. About $66 \%$ of those who were infected had egg output of 50 eggs or more $/ 10 \mathrm{ml}$. of urine. One female had an output of 180 eggs $/ 10 \mathrm{ml}$. of urine.

The relationship between water contact habits of males and females to prevalence showed that among male students $41.2 \%$ engaged in swimming activities whereas only $29.3 \%$ of females were involved. Also $36.7 \%$ of the males and $32.6 \%$ of the females actually bathed in the Kakum river. Other activities in the water like washing of dishes and clothes attracted $22.0 \%$ and $38.0 \%$ of males and females respectively.

Knowledge of the disease was very tittle, with about $61.2 \%$ having no idea of what causes the disease, while $12.5 \%$ thought that it was caused by contact with a body of water. Some 15.6\% believed that it was caused by drinking of dirty water.

There was no relationship between prevalence and weight to height ratio. Also there was no relationship between sex and prevalence. Relationships however existed between the paternal occupational groups and between the maternal occupational groups using the Chi square test.

For paternal occupational groups, Calculated $\chi^{2}=12.595$

Tabulated $\chi^{2}=3.841$

For maternal occupational groups,

$$
\begin{aligned}
& \text { Calculated } \chi^{2} 7.429 \\
& \text { Tabulated } \chi^{2}=3.841
\end{aligned}
$$

Thus we accept alternative hypotheses in both cases. 


\section{DISCUSSION}

Before the onset of this study information was obtained from the Regional Health Office that $S$. haematobium was prevalent in this area, but recent published data were not available to cover the information obtained in this study. This study has indicated a prevalence of $34,4 \%$ among the students of Twohofo Holy International School. This is high. Parental occupation has influence on prevalence, with children of salaried workers exhibiting less prevalence than children of those who do other jobs. This observation agrees with the results obtained by Okanla (1991), in llorin, Nigeria. The relationship between schistosomiasis and occupation has long been known (Edungbola, 1980; Fenwick and Jorgensen, 1972). Also contact with water for recreational or other activities has also been associated with infections with schistosomes. (Fernwick and Jorgensen, 1972).

This study utilized the centrifugal sedimentation method to finally determine the number of eggs in $10 \mathrm{ml}$. of urine (Okanla 1991). This method is very sensitive since it utilizes the total urine passed by the subject.. It is however not as fast as the membrane filtration technique which uses a nylon mesh to filter a sample of $10 \mathrm{ml}$. drawn from the total urine passed by each subject. The membrane method is therefore more frequently used for epidemiological purposes. This study was intended to look at overall prevalence as well as determine the epidemiological significance of the disease. The sedimentation method was therefore preferred.

Single urine samples only were examined in this study, although multiple examinations may reveal slightly higher prevalence. Two thirds of the infected subjects passed more than 50 eggs per $10 \mathrm{ml}$. of urine, which is considered to be epidemiologically significant. One girl passed 180 eggs $/ 10 \mathrm{ml}$ urine. This was very high. $S$. haematobium infections may cause discomfort, but rarely lead to death. However, when intensity of infection is so high mortality may eventually result (Mahmoud, 1987). Significant difference did not exist in the nutritional status of infected and uninfected subjects. This agreed with the findings of others (Hiatt et al, 1977; Lehman et at. 1976; Hiatt 1976; Cook et a!. 1974; Okanla 1991). This study also showed that most of the subjects had no idea of the cause of the disease. Good education is therefore needed in order to increase the general awareness of people in the community.

ACKNOWLEDGEMENT: This study was supported by Students Project Funds of the Faculty of Science, University of Cape Coast.

\section{REFERENCES}

Adams A.R.D. and Maegraith B.G. (1976): In: Clinical Tropical Diseases (Ed. B.G. Maegraith): Blackwell Scientific Publications, Osney, Oxford. p1359.

Edungbola, L.D. (1980). Water utilization and its health implication in llorin, Kwara State, Nigeria. Acta Tropica 37:79-8 1.

Okanla E.O. (1991). Schistosomiasis: Influence of parental occupation and rural or urban dwelling on prevalence. Nig. J. Pure \& Appl. Sd.. 6(1991): 154-159.

Fernwick, A. and Jorgensen, T.A. (1972). The effect of control program against Schisiosoma mansoni on the prevalence and intensity of infection on an irrigated sugar estate in Northern Tanzania. Bull. Wld. Huh. Org. 47: 579-586.

Hiatt, R.A. (1976). Morbidity from Schistosoma mansoni infections: An epidemiologic study based on quantitative analysis of egg excretion in two Highland Ethiopian villages. Am. J. Trop. Med. Hyg. 25: 808-8 17.

Hiatt, R.A. and Gebre-medhin, M. (1977). Morbidity from Schistosoma mansoni infections: An epidemiologic study based on quantitative analysis of egg excretion in Ethiopian children. Am. J. Trop. Med. Hyg. 26:473-48 1.

Lehman, J.S. Jr., Mott, K.E., Morrow, R. H. Jr., Munitz, T.M. and Boyer, M.H. (1976). The intensity and effects of infections with Schisiosoma mansoni in a rural community in north east Brazil, Am. J. Trop. Med. Hyg. 25: 285-294.

Cook, J.A., Baker, S.T. Warren, KS. and Jordan, P. (1974). A controlled study of morbidity of Schistosomiasis mansoni in St. Lucian children based on quantitative egg excretion. Am. J. Trop. Med. Hyg. 23: 625-63 
